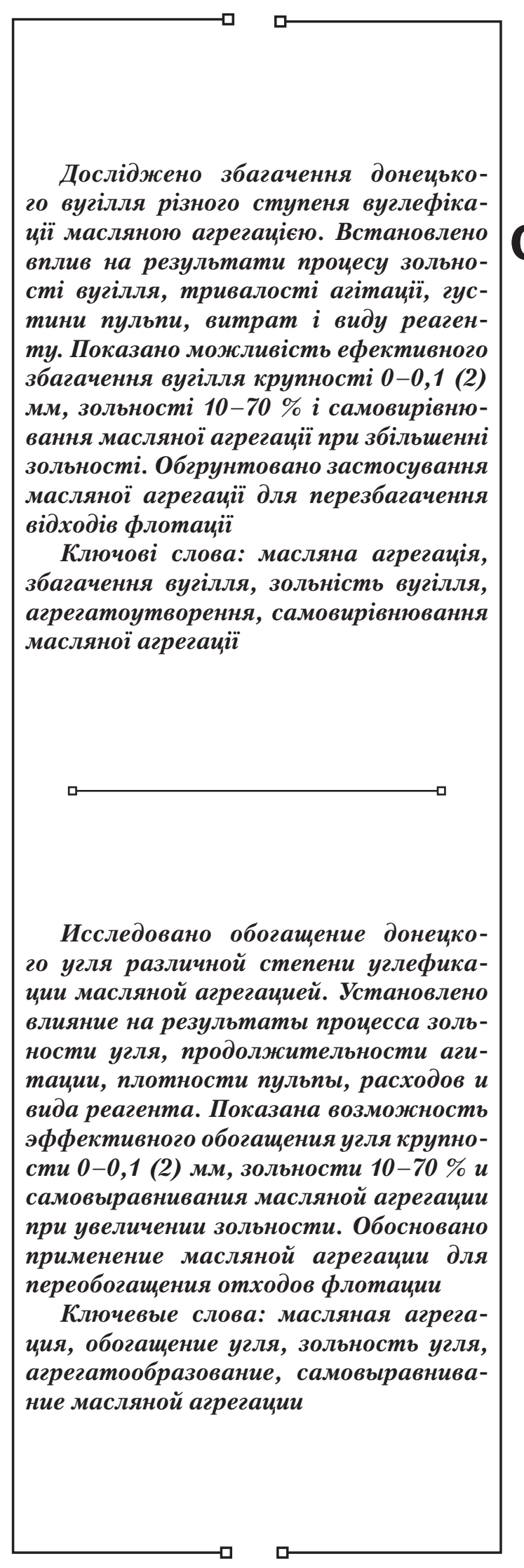

UDC 622.765.063.24

DOI: $10.15587 / 1729-4061.2017 .104123$

\title{
RESEARCH INTO THE PROCESS OF PREPARATION OF UKRAINIAN COAL BY THE OIL AGGREGATION METHOD
}

V. Bilets $\mathbf{k}$ i

Doctor of Technical Sciences, Professor, Head of Department*

E-mail: ukcdb@i.ua

P. Molchanov

$\mathrm{PhD*}$

E-mail: petja_men@ukr.net

M. Sok u r

Doctor of Technical Sciences, Professor

Department of marketing

Kremenchuk Mykhailo Ostrohradskyi National University

Pershotravneva str., 20, Kremenchuk, Ukraine, 39600

G. G a y k o

Doctor of Technical Sciences, Professor Department of Mining and Technology Geobuilding National Technical University of Ukraine "Igor Sikorsky Kyiv Polytechnic Institute" Peremohy ave., 37, Kyiv, Ukraine, 03056

E-mail: g.gayko@kpi.ua

V. S a v y k

$\mathrm{PhD*}$

E-mail: savicppntu@rambler.ru

V. Orlovsky y

$\mathrm{PhD*}$

E-mail: svaroh13@ukr.net

M. Li ak h

PhD, Professor

Department of Oil and Gas Equipment**

E-mail: mm.lyakh@gmail.com

T. Y a t s y s h y

$\mathrm{PhD}$, Associate Professor

Department of ecology**

E-mail: yatsyshyn.t@gmail.com

R. F u r s a

Postgraduate student

Department of Oil and Gas Equipment**

E-mail: FursaRP@i.ua

*Department of the equipment of oil and gas fields

Poltava National Technical Yuri Kondratyuk University

Pershotravnevyi ave., 24, Poltava, Ukraine, 36011

**Ivano-Frankivsk National Technical University of Oil and Gas

Karpatska str., 15, Ivano-Frankivsk, Ukraine, 76019

\section{Introduction}

Modern advanced mechanized techniques of coal mining predetermine content of finely dispersed fractions the size of $0-1 \mathrm{~mm}$ in ordinary coal at the level of $3.2-40 \%$. Taking into account sludge generation during transportation and preparation, the content of finely dispersed fractions increases to $50-60 \%$ [1]. Processing of this raw material 
is a big problem, especially for finely dispersed fractions of $0-0.15(0.2) \mathrm{mm}$, whose preparation efficiency by gravitation methods (jigging, heavy-medium hydrocyclones, hydrosizer) is significantly lower. The only widely used method of primary processing (coal preparation, dressing) of finely dispersed fractions of coal at present is flotation [2]. However, efficiency of extraction of coal grains the size of $0.05 \mathrm{~mm}$ into flotation concentrate is not high. The reason for this is a low mass of coal micro grains that proceed along the lines of fluid flow and bend around the bubbles of air. Thus, they are not at all involved in the process of flotation [2]. There had been efforts to overcome the indicated difficulties by employing column flotation, which is more efficient for fine grades, "turbulent micro flotation" or TMF-technology, by using "flotation with a carrier", etc. [3]. Thus, the main problem that needs further investigation is the preparation of coal $-0.05 \mathrm{~mm}[2,3]$.

The most effective way of solving the problem of preparation of finely and thinly dispersed (especially ultra-thin) coal is preliminary selective aggregation. For example, flocculation, agglomeration, granulation in aqueous medium by a hydrophobic reagent with subsequent separation and processing of product [4-6]. Industrial testing showed high efficiency of preparation of coal the size of $0-0.15(0.2) \mathrm{mm}$, including ultra-thin grade of $0-0.05 \mathrm{~mm}$, by selective oil flocculation (the process "OVZUMS"), by implementing oil agglomeration and granulation [4, 5], selective latex flocculation [6]. In this case, it should be emphasized that the scope of practical application of selective aggregation of thin coal includes both the sludge of preparation factory (water-sludge system) and aged coal-containing material of preparation waste in sludge accumulators [7].

Therefore, oil aggregation as a specialized processing method of Ukrainian finely- and thinly dispersed coal is a promising issue. The actual task is to examine the application of this method for preparation the Donetsk coal of varying degrees of coalification and to establish character of the impact of main variation parameters on the results of oil aggregation of coal.

\section{Literature review and problem statement}

Article [8] shows that the results of the process of oil agglomeration of finely dispersed coal are influenced by the type of oil, size of coal particles and the magnitude of water environment $\mathrm{pH}$. In the experiments, as a binder, they used castor and rapeseed oil, which, respectively, enabled $75 \%$ and $64 \%$ yield of agglomerates. Calorific value of coal-oil agglomerates reached $6.257 \mathrm{kcal} / \mathrm{kg}$ compared to $4903 \mathrm{kcal} / \mathrm{kg}$ for the original coal. In this case, the content of ash in the coal fuel decreased by $66 \%$. These indicators allowed the authors to evaluate the process of oil agglomeration for finely dispersed coal as effective. However, the chosen variable input factors do not take into account hydrodynamic parameters of the pulp, which affect the process of pelletizing (aggregation).

During oil agglomeration of finely dispersed Chinese coal, vegetable oil was used as a binder [9]. Dimensionality of the original coal: $-75 ; 75-150 ; 150-212 ; 212-300 \mu \mathrm{m}$. Consumption of oil-binder to coal $-25 \%$ by weight. The ratio of "coal:water" in the pulp is 15:200. Variable parameters: agitation duration and speed of the mixer's impeller. Authors examined effect of dimensionality of the original material on results of the process, of rotation speed of the mixer's impeller, of agitation duration. The highest index of process efficiency was obtained for the original coal of 0-75 mm. Agitation mode in all experiments is turbulent, but authors registered a decline in the index of process efficiency at a speed of impeller of $2000 \mathrm{~min}^{-1}$; at 1000 and $2500 \mathrm{~min}^{-1}$ this index is relatively higher. The effect of agitation duration on results of the process was explored in the range of 5-25 min, while the important period of $0-5$ min. remained unexamined. The largest index of process efficiency was registered on minute 15 and it little changed subsequently. An important and positive feature of study [9] is the infrared spectroscopy of the binder - vegetable oil, which made it possible to identify functional groups, which provide the possibility to characterize structure of the reagent. The resulting empirical material is very valuable. In particular, authors determined rational limits of the speed of impeller and duration of pulp agitation, dimensionality of the original coal. The received IR spectra reveal functional groups in reagent-binder that enhance the interaction of "coal-reagent". However, the study is fragmented and of ascertaining nature, failing to explain the effect of aggregation. In addition, all results are related only to the examined Chinese coal.

Oil agglomeration of "salty coal", as follows from study [10], has its own special features. This coal is typically low-metamorphosed and is characterized by a high content of salts of alkali metals, first of all, sodium $(\mathrm{NaCl}, \mathrm{KCl})$. Therefore, the surface of the "salt coal" is highly hydrophilic. In order to hydrophobize the coal, authors in [10] proposed an additional operation - preliminary mechanical treatment with the addition of a small amount (to $1 \%$ by weight) of oil-binder. This operation provides mechanochemical activation and subsequent hydrophobicization of surface of the solid phase of coal. The latter is a mandatory condition for the formation of coal-oil aggregates. A positive outcome of the given study is experimental confirmation of the special role of coal hydrophobicity in achieving the aggregation of coaloil phase in a hydro-mixture. The mechanism of aggregation remains beyond attention and is not considered at all, while results of research are related to the salty coal only, and, as to be expected, hydrophilic (weathered) analogs.

When preparation the Fujian coal with oil agglomeration, article [11] highlighted the following basic factors that affect the process: concentration of coal in the pulp, consumption of oil-binder, type of oil (they used petroleum; rapeseed oil). Results revealed that at concentration of coal in slurry of $11.1 \%$ and consumption of oil $12.5 \%$, the ash content can be reduced from $32 \%$ to $2.8 \%$, ash content in waste amounts to $93.0 \%$. This confirmed high efficiency of aggregation processes and coal extraction by different hydrophobic reagents from a diffused hydro-mixture (suspension with a concentration of solid $11 \%$ ). In addition, important for the rational choice of rational operational process parameters is the registration of consumption of oil-binder $(12.5 \%)$. The mechanism of aggregation process is not considered. The selected variable input factors, similar to paper [8], do not take into account hydrodynamic parameters of the pulp, which affect the process of selective pelletizing of coal-oil aggregates. Resulting numerical indicators are related to the preparation of Fujian coal.

Study [12] established the following factors that influence the process of oil aggregation of stone coal: type of oil, the content of coal in the pulp, oil content, agglomeration duration, dimensionality of original coal, agglomeration, $\mathrm{pH}$ 
of the pulp, rate of agitation. Authors registered not only ash content reduction, but also desulphurisation of the original coal. The latter has great practical value, since the content of sulphur in coal concentrate considerably determines ecological component of subsequent application as fuel or for the preparation of coke charge. Positive is a wide range of technological factors that influence the process, described by authors. At the same time, the mechanism of aggregation was not considered, the impact of physical-chemical characteristics of coal (except dimensionality) on the results of the process was not studied.

The process of oil agglomeration has been explored by several scientific schools for the desulphurization and deashing of lignite (brown coal). Paper [13] established the following technological factors of influence on the process of oil agglomeration of brown coal: concentration of the solid in the pulp, consumption of oil-binder, agglomeration duration, and type of oil. In this case, they applied different hydrocarbon oils - toluene, diesel fuel, and pine oil. Calorific value of the sample of lignite increased to $2190 \mathrm{kcal} / \mathrm{kg}$ from $1687 \mathrm{kcal} / \mathrm{kg}$. Obtained results confirm the possibility of refining (deashing, aggregation, desulphurization) by oil agglomeration not only stone coal, but brown coal as well. However, the mechanism of the process, as is the case for the above studies, was not investigated, the obtained results are related to the low-metamorphosed coal.

The first part of study [14] establishes impact of the following factors on the preparation of brown coal by oil agglomeration: concentration of the solid in the pulp, consumption of oil-binder, type of oil, $\mathrm{pH}$ of the liquid phase. They in particular determine the results of deashing and desulphurization of coal. In fact, the obtained results confirmed known data $[12,13]$ about the decisive influence of the above-mentioned technological factors on the process. The second part of research examines the influence of aqueous phase on the progress and results of the process: lake water and seawater (the water of the Mediterranean Sea, Aegean Sea, and the water of the Black Sea). A similar study into effect of the Mediterranean water on the desulphurisation of coal by oil agglomeration was carried out when using as a raw material subbituminous (longflame) coal from Zonguldak [15]. The third part of study [15] investigated the effect of various salts $\left(\mathrm{NaCl}, \mathrm{MgCl}_{2}\right.$ and $\mathrm{FeCl}_{3}$ ) on the agglomeration of lignite. Results of agglomeration revealed that the use of calcinated lake water and seawater had a positive effect on the reduction of total sulfur content in agglomerates. In addition, the application of $\mathrm{NaCl}, \mathrm{MgCl}_{2}$ and $\mathrm{FeCl}_{3}$ in agglomeration environment has a positive effect on the reduction of ash content in agglomerates. Of absolute practical value in this study is the confirmation of the possibility of successful process of oil agglomeration of coal not only in fresh water, but in the salty as well, in particular, seawater. However, chemistry of the processes, parametric constraints of salinated water phase is not explored. Obtained results, as is the case in previous study [13], apply to the low-metamorphosed coal.

Thus, rich experimental material highlights sufficiently enough key technological factors that influence the process of oil aggregation of coal. The main technological factors are the type and consumption of oil-binder, dimensionality of original coal, magnitude of aqueous medium $\mathrm{pH}$, the ratio "coal:water" in the pulp, agitation duration and speed of the mixer's impeller. At the same time, results of the process of oil aggregation are significantly affected by characteris- tics of the original enriched coal, in particular, the degree of coalification, ash content, conditions of formation and deposition of the deposit method of extraction, conditions of formation and location of deposit, etc. That is why some studies-analogs outline similar qualitative trends in the influence of factors on the results of coal preparation by oil aggregation. At the same time, quantitative results of research are typically different by the influence of the specified factors on the indicators of coal concentrate and waste obtained during coal preparation from different deposits and fields.

\section{The aim and objectives of the study}

The goal of present study is to examine preparation of Donetsk coal of varying degrees of coalification by the method of oil aggregation. This will provide a possibility to determine rational limits in the process operational parameters, as well as to establish technological capacities of oil aggregation, in particular, by the content of ash and dimensionality of the original enriched coal.

To accomplish the set goal, the following tasks had to be solved:

- to establish the character of impact of the ash content in the original coal on the results of oil aggregation;

- to examine effect of the pulp agitation duration and pulp density on the results of oil aggregation of coal;

- to explore influence of consumption and the type of reagent-binder on the results of oil aggregation of coal.

\section{Materials and methods for examining the process of preparation of Donetsk coal by the method of oil aggregation}

\section{1. Examined materials and equipment}

We examined Donetsk coal - anthracite the size of $0-100 \mu \mathrm{m}$ and coal of the grade $\mathrm{G}, 0-100 \mu \mathrm{m} ; 0-1 \mathrm{~mm}$; $0-2 \mathrm{~mm}$.

As a reagent-binder, when pelletizing coal, we used anthracene oil, polymer of benzol production (PBP) from Avdyivka KKhZ (Ukraine), a mixture of "briketin: kerosene" $=1: 3$, oil fuel M100.

We used the following equipment in the processing and preparation of coal.

Laboratory crusher: includes 4 crushing pairs "cup-rod", which are placed on the frame of the crusher. The latter is on the rubber suspensions. The system is set into oscillating motion by electric motor. As a result, the rod moves along the wall of the cup and grinds the sample of the material downloaded into the cup.

In order to obtain original material of the assigned dimensionality and to sift the granules - sieve vibration analyzer.

Laboratory setup for the realization of the process of oil aggregation of coal included a turbulent mixer with electric drive, which enabled a change in the frequency of shaft rotation within $0-70 \mathrm{~s}^{-1}$. Working chamber of the mixer is a cylinder with a diameter of $15 \mathrm{~cm}$ and a volume of the working chamber 21 . Impeller has four blades with a diameter of $3 / 4$ of the diameter of the working chamber. To warm the reagent, there is a cup electric heater.

To dispense the reagent, we used a measuring syringe. For the preparation of water-coal pulp with assigned struc- 
ture (density), we used measuring glassware and laboratory scales.

For the dehydration of coal-oil concentrate by draining - laboratory installation in the form of a pipe with height $1.2 \mathrm{~m}$, diameter $100 \mathrm{~mm}$, which is leaned against a sieve with cells of $0.5 \mathrm{~mm}$.

\section{2. Procedure of research}

In order to measure $\mathrm{pH}$, we applied the $\mathrm{pH}$-meter MARK-902MP, to measure temperature of reagent $t_{\mathrm{r}}$ and pulp $t_{\mathrm{s}}$ - mercury thermometer, to measure pelletizing duration $\tau_{\mathrm{a}}-$ a stopwatch, to measure rotation speed $\mathrm{n}_{\mathrm{s}}$ of the mixer's impeller - a tachometer.

For the visual identification of the type of mechanism of the process of oil aggregation of coal - "coalescence" or "amalgam" - we used a stroboscope.

For the visual identification of aggregated and non-aggregated coal, we used the microscope MBS-9v.

Outer specific surface of the original coal $\mathrm{S}_{S S A}$ was determined using the method of Tovarov.

Ash content $\mathrm{A}^{\mathrm{d}}$ of coal and tails (waste) was defined in line with GOST 11022-95 (ISO 1171-97) "Fuel, solid, mineral. Methods for determining ash content". Humidity of coal-oil concentrate after draining $\mathrm{W}_{\mathrm{tk}}^{\mathrm{r}}$ - according to GOST 27314-91 (ISO 589-81) "Fuel, solid, mineral. Methods for determining moisture content".

The mean diameter of coal-oil aggregates $d_{a}$ was calculated based on data of sieve analysis as the arithmetic weighted average.

The yield of aggregated coal-oil concentrate $\gamma_{c}$ was determined as a share (\%) of aggregated coal to the non-aggregated in the field of the microscope MBS-9v.

\section{Research results of the process of preparation of Donetsk coal by the method of oil aggregation}

First series of experiments. Variable factors - ash content of the original coal $\mathrm{A}^{\mathrm{d}}$, agitation duration $\tau_{\mathrm{a}}$ and pulp density $\rho_{\mathrm{ws}}$.

Impact of the ash content of original coal and pulp agitation duration on the results of oil aggregation is shown in Fig. 1.

Mode of the process: examined coal - anthracite the size of $0-100 \mu \mathrm{m}$; the liquid phase of the pulp: index $\mathrm{pH}=7$; consumption of oil reagent $\mathrm{Q}_{\mathrm{r}}=32 \%$ by weight; oil reagent (binder) - oil fuel M100; $\rho_{\mathrm{ws}}=350 \mathrm{~g} / \mathrm{l}$; pulp temperature $\mathrm{t}_{\mathrm{s}}=70^{\circ} \mathrm{C}$; rotation frequency of mixer's impeller $\mathrm{n}_{\mathrm{s}}=20 \mathrm{~s}^{-1}$.

Experimentally obtained dependence of change in the extraction of anthracite $\varepsilon_{\mathrm{E}}$ on the duration of pulp agitation at high $(60-70 \%)$ and lower (10-40\%) ash content of solid phase has the character of an exponential function with different curves. In this case, an increase in the ash content above $50-60 \%$ leads to a qualitative change in the processes of extraction, which is expressed by the change of curve shape $\varepsilon_{\mathrm{E}}\left(\tau_{\mathrm{a}}\right)$ - Fig. 1 (family of curves $1-3$, and 4,5 ) and by a sharp decrease in the speed of aggregation.

Dependences of the speed of aggregation $V_{a}$ on the density of water-coal mixture $\rho_{\mathrm{ws}}$ at different ash content of coal are shown in Fig. 2. Mode of the process: $\mathrm{pH}=9, \mathrm{Q}_{\mathrm{r}}=20 \%$ by weight (oil fuel M100), $\mathrm{t}_{\mathrm{r}}=70-80^{\circ} \mathrm{C}, \mathrm{t}_{\mathrm{s}}=25^{\circ} \mathrm{C}, \mathrm{n}_{\mathrm{s}}=40 \mathrm{~s}^{-1}$, coal of grade $\mathrm{G}, 0-100 \mu \mathrm{m}$. This family of curves has two distinguishing features. First, there is a vividly expressed extreme shape of curve $V_{a}\left(\rho_{w s}\right)$, that is, for each ash content of the solid-phase there is the optimal pulp density, at which the rate of aggregation $\mathrm{V}_{\mathrm{a}}$ is maximal. In this case, the peak of maximal speed of aggregation $\mathrm{V}_{\mathrm{a}}$ for the lower ash contents is significantly larger than that for high values of ash content of the processed material. Thus, at ash content of solid phase of the pulp $15 \% \mathrm{~V}_{\mathrm{a}} \max 22.3 \mathrm{~mm} / \mathrm{min}$, and at ash content of $65 \% \mathrm{~V}_{\mathrm{a}} \max 3.5 \mathrm{~mm} / \mathrm{min}$. Second, for low-ash pulps, peaks $\mathrm{V}_{\mathrm{a}}$ max are in the region of their high densities (350$450 \mathrm{~g} / \mathrm{l}$ ), while for the high-ash pulps, peaks $\mathrm{V}_{\mathrm{a}}$ max are in the region of low densities $(50-150 \mathrm{~g} / \mathrm{l})$. An increase in the ash content of solid phase in the pulp leads to slowing down the extraction of organic mass into granules (Fig. 1) and a decrease in the speed of aggregation (Fig. 2).

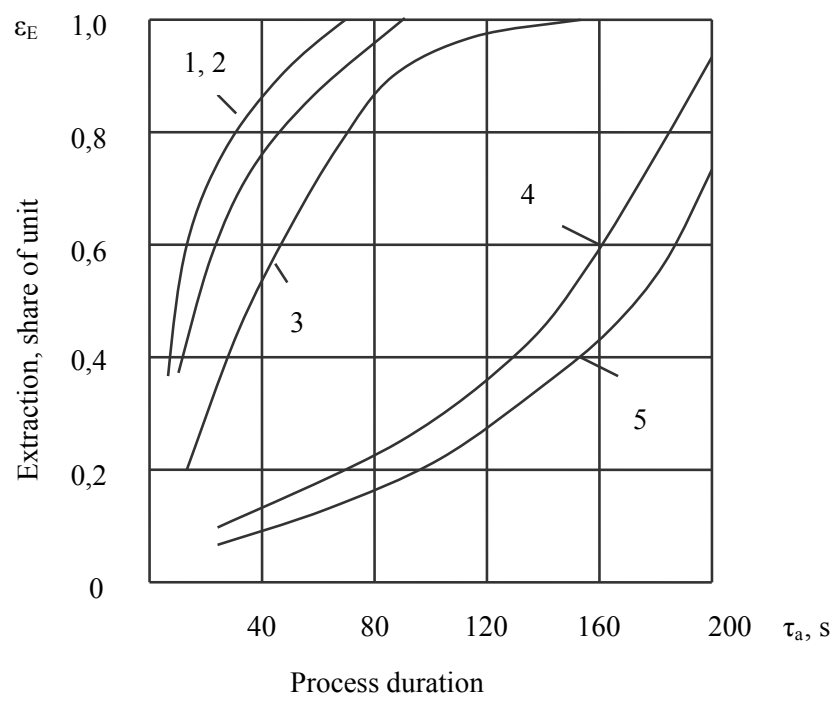

Fig. 1. Kinetic curves of extraction of anthracite $\varepsilon_{E}\left(\tau_{a}\right)$ into coal-oil agglomeration concentrate at different ash content of original coal $A^{\mathrm{d}}$ : $1-10 \% ; 2-20 \% ; 3-40 \% ; 4-60 \% ; 5-70 \%$

\section{$\mathrm{V}_{\mathrm{a}}, \mathrm{mm} / \mathrm{min}$}

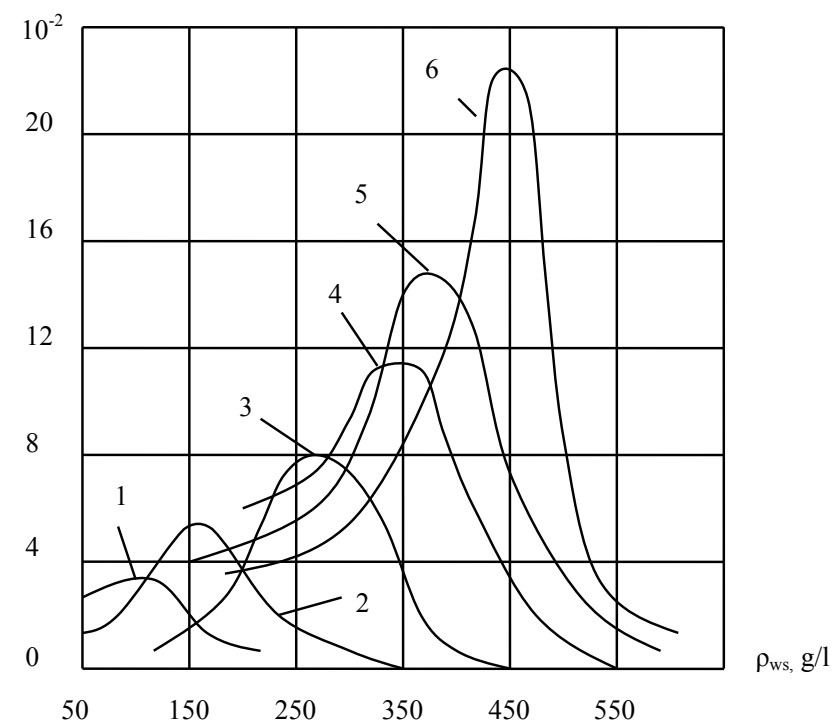

Fig. 2. Experimental dependences of the rate of aggregation $\mathrm{V}_{\mathrm{a}}$ on density of water-coal suspension $\rho_{\mathrm{ws}}$ at different ash content of coal $A^{\mathrm{d}}$ : $1-65 \% ; 2-55 \% ; 3-45 \% ; 4-35 \%$; $5-25 \% ; 6-15 \%$ 
Second series of experiments. Variable factors - the type and consumption $Q_{\mathrm{r}}$ of the reagent-binder. Fig. 3 shows experimental dependences on the consumption of reagent-binder of "tails" (wastes) of oil aggregation $\mathrm{A}_{\mathrm{w}}^{\mathrm{d}}\left(\mathrm{Q}_{\mathrm{r}}\right)$, mean diameter of coal-oil aggregates $d_{a}\left(Q_{r}\right)$, obtained for coal of grade $G$ the size of $0-1.0 \mathrm{~mm}$, size grade $-0.1 \mathrm{~mm}$ $39.7 \%, \mathrm{~S}_{\mathrm{SSA}}=1590 \mathrm{~cm}^{2} / \mathrm{g}, \mathrm{A}_{\mathrm{c}}^{\mathrm{d}}=10 \%$.

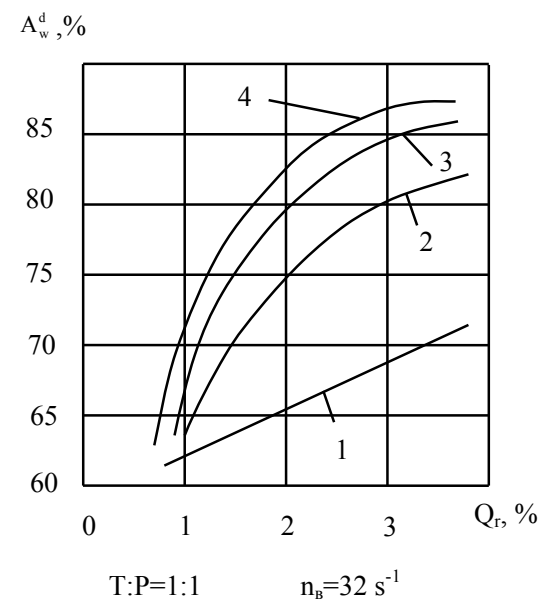

Fig. 3. Experimental dependences $A_{w}^{d}\left(Q_{r}\right)$, pulp agitation duration $\tau_{\mathrm{a}}: 1-1 \mathrm{~min} ; 2-3 \mathrm{~min} ; 3-5 \mathrm{~min} ; 4-10 \mathrm{~min}$

$\mathrm{d}_{\mathrm{a}}, \mathrm{mm}$

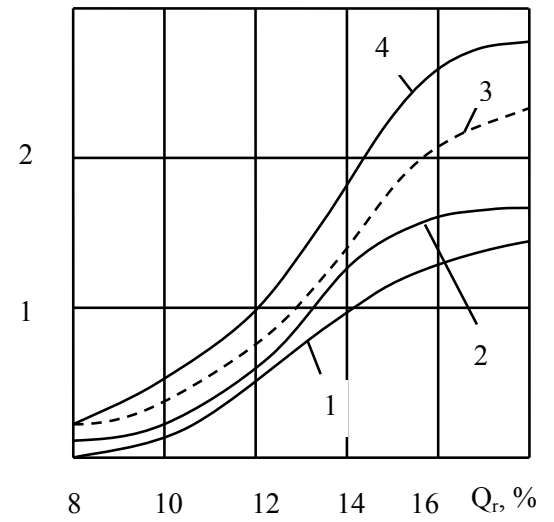

Solid:liquid=1:1,5 $\quad \mathrm{n}_{\mathrm{s}}=25 \mathrm{~s}^{-1} \quad \tau_{\mathrm{a}}=10 \mathrm{~min}$

Fig. 4. Experimental dependences $d_{a}\left(Q_{r}\right) .1$ - anthracene oil; 2 - polymer of benzol production (PBP) from Avdyivsky KKhZ; 3 - mixture "briketin:kerosene"=1:3; $4-$ oil fuel M100

The character of experimental dependences $A_{w}^{d}\left(Q_{r}\right)$, and $\mathrm{d}_{\mathrm{a}}\left(\mathrm{Q}_{\mathrm{M}}\right)$ except $\mathrm{A}_{\mathrm{w}}^{\mathrm{d}}\left(\mathrm{Q}_{\mathrm{r}}\right)$, at $\tau_{\mathrm{a}}=1 \mathrm{~min}$. is non-linear with a tendency to flattening.

For dependences $A_{w}^{d}\left(Q_{r}\right)$, flattening of curves is observed at $Q_{r} \geq 3 \%$ by weight and $\tau_{a} \geq(3-10) \mathrm{min}$. In this case, the ash content of waste $A_{w}^{d}$ reaches $82-87 \%$.

For dependences $d_{a}\left(Q_{M}\right)$, flattening of curves is observed at $Q_{r} \geq 16 \%$ by weight. In this case, maximal size of coal-oil aggregates under specified operational parameters is achieved for $\mathrm{Q}_{\mathrm{r}}=18 \%$ by weight. In this case, the average diameter of coal-oil fuel aggregates is reduced in this range of utilized reagents: oil fuel - a mixture "briketin-kerosene" - PBP anthracene oil $(2.8 ; 2.3 ; 1.8 ; 1.4 \mathrm{~mm}$, respectively).

Figs 5, 6 show obtained dependences of a number of input parameters of the process on the consumption of re- agent-binder: yield of aggregated coal-oil concentrate $\gamma_{\mathrm{c}}\left(\mathrm{Q}_{\mathrm{r}}\right)$, its humidity $W_{\mathrm{tk}}^{\mathrm{r}}\left(Q_{\mathrm{r}}\right)$, the original coal was of grade $\mathrm{G}$ the size of 0-2 mm, reagent-binder - oil fuel M100.

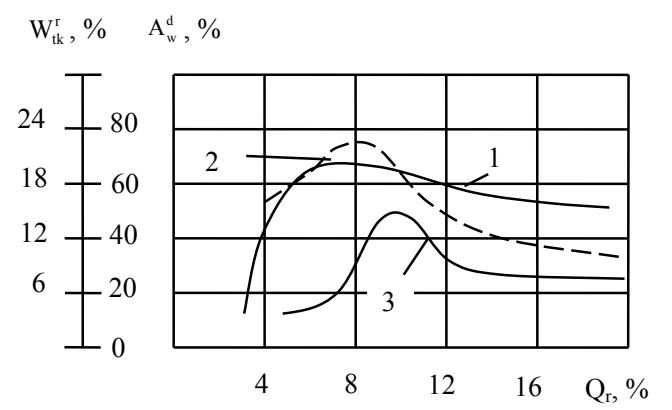

Fig. 5. Experimental dependences $A_{w}^{d}\left(Q_{r}\right)$ and $W_{t k}^{r}\left(Q_{r}\right)$ : $1-A_{\mathrm{w}}^{\mathrm{d}}\left(Q_{\mathrm{r}}\right), 2,3-\mathrm{W}_{\mathrm{tk}}^{\mathrm{r}}\left(Q_{\mathrm{r}}\right)$ in one and two days of draining, respectively

$\gamma_{\mathrm{c}}\left(\mathrm{Q}_{\mathrm{r}}\right), \%$

8

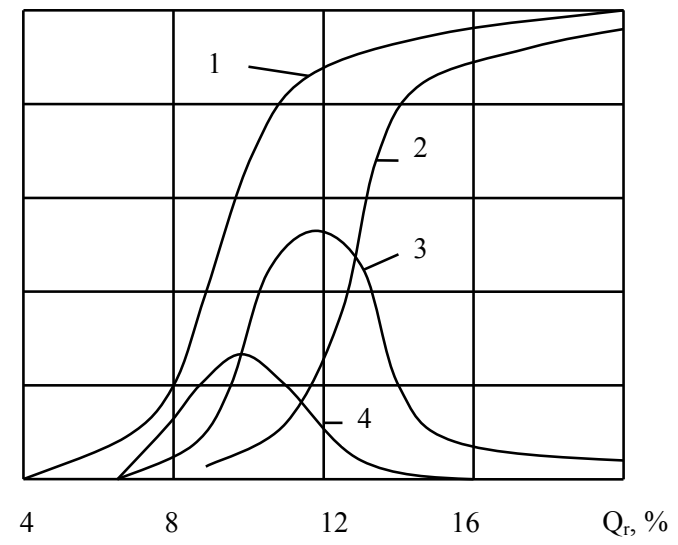

Fig. 6. Experimental dependences $\gamma_{c}\left(Q_{r}\right): 1-$ total yield of granules; $2-$ yield of granules of size grade $+1.6 \mathrm{~mm}$; 3 - size grade $1.6-1.0 \mathrm{~mm} ; 4-$ size grade $1.0-0.5 \mathrm{~mm}$

Dependence $\mathrm{A}_{\mathrm{w}}^{\mathrm{d}}\left(\mathrm{Q}_{\mathrm{r}}\right)$, has a smooth extremum-maximum $\mathrm{A}_{\mathrm{w}}^{\mathrm{d}} \approx 68 \%$ in region $\mathrm{Q}_{\mathrm{r}}=(6-8) \%$ by weight.

Curves of draining the coal-oil agglomerate $\mathrm{W}_{\mathrm{tk}}^{\mathrm{r}}\left(\mathrm{Q}_{\mathrm{r}}\right)$ are extreme in character, too. In this case, aggregates are actively drained at $Q_{1}>10 \%$ by weight. Humidity of the dewatered coal-oil agglomerate over 2 and 3 days of draining for $\mathrm{Q}_{\mathrm{r}}=16 \%$ is, respectively, $11 \%$ and $8 \%$ (Fig. 5, 6).

The total yield of the aggregated coal-oil concentrate $\gamma_{c}\left(Q_{r}\right)$, that is, the degree of involvement of coal in the coaloil aggregates during oil aggregation, at $\mathrm{Q}_{\mathrm{r}}=18 \%$ by weight, reaches $100 \%$ (the entire coal phase is aggregated). The yield of the coal-oil aggregates of size grade of 1.6-1.0 mm, and $1.0-0.5 \mathrm{~mm}$, has extreme character (Fig. 11).

Fig. 7-10 show coal-oil aggregates-granules and conglomerates of granules obtained in the described experiments based on Donetsk coal and fuel oil M100. Fig. 11 shows their polished sections.

Habitus of coal-oil aggregates from coal of $0-100 \mu \mathrm{m}$, obtained at consumption of fuel oil $20 \%$ by weight is characterized (Fig. 7, 8) by rounded shapes, peddle-shaped (eggshaped). Instead, coal-oil aggregates from coal of 0-1 mm (Fig. 9,10) possess angular shapes, indicating only partial involvement of large grains into oil aggregation. Larger grains serve the centers of aggregation while the granules are essentially structures of the type "center-shell" (Fig. 11). 


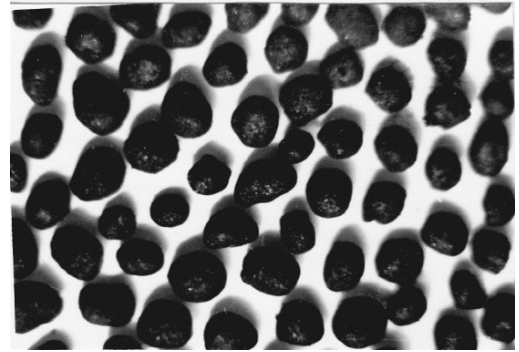

Fig. 7. Coal-oil fuel aggregates-granules obtained based on Donetsk coal of $0-100 \mu \mathrm{m}$. The mean dimensionality of aggregates is $3-4 \mathrm{~mm}$

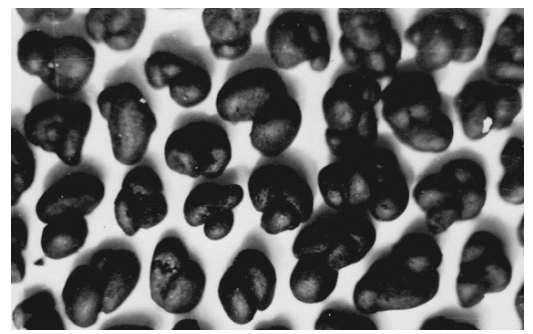

Fig. 8. Coal-oil fuel conglomerates of granules obtained based on Donetsk coal of $0-100 \mu \mathrm{m}$

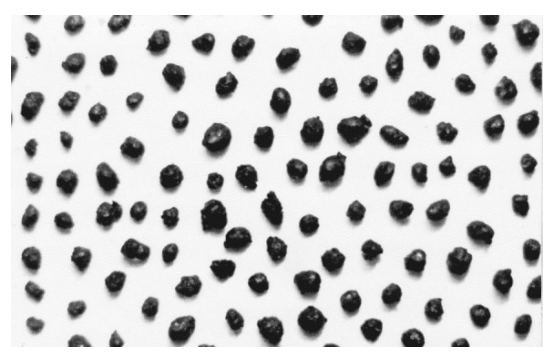

Fig. 9. Coal-oil fuel aggregates-granules obtained based on Donetsk coal of $0-1 \mathrm{~mm}$. The mean dimensionality of aggregates is $2-3 \mathrm{~mm}$

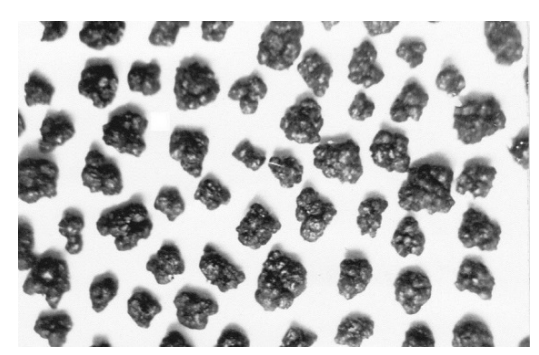

Fig. 10. Coal-oil fuel conglomerates of granules obtained based on Donetsk coal of $0-1 \mathrm{~mm}$

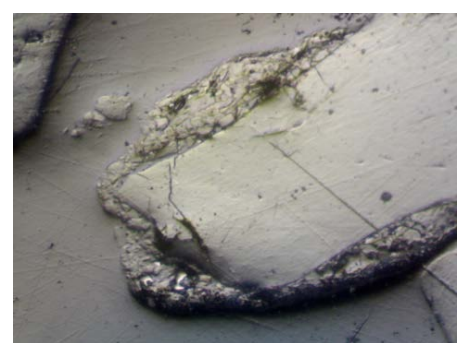

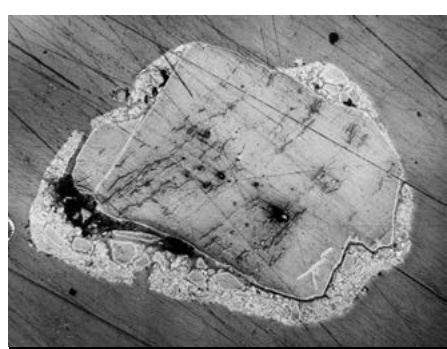

$b$
Fig. 11. Polished sections of coal-oil fuel of aggregates-granules

(Fig. 9), obtained based on Donetsk coal the size of $0-1 \mathrm{~mm}$ : $a-$ magnification $\times 200 ; b-$ magnification $\times 150$
6. Discussion of results of examining the process of preparation of Donetsk coal by the method of oil aggregation

First series of experiments. The impact of the ash content of original coal on the results of oil aggregation (Fig. 1, 2) unambiguously demonstrates substantial (4 times and larger) reduction in the speed of aggregation in high-ash pulps at an increase in the ash content of solid phase of the pulp from $15 \%$ to $65 \%$. This is obviously due to the lower probability of interaction between coal particles in high-ash pulps where they (are at greater distances) and are partially blocked by the rock grains. The latter are in the intervals between grains of coal and hinder their contact and adhesion.

Curves $\varepsilon_{\mathrm{E}}\left(\tau_{\mathrm{a}}\right)$ that are the dependences of coal extraction from a hydro-mixture $\varepsilon_{\mathrm{E}}$ on the agitation duration $\tau_{\mathrm{a}}$, obtained for anthracites, can be considered standard since for coal of other stages of metamorphism they are similar and approximated by exponential dependence [4]:

$$
\varepsilon(\tau)=\varepsilon_{\max }(1-\exp (-\mathrm{k} \tau)
$$

where $\varepsilon_{\max }=0.94$.

In this case, correlation ratio for the regression and the curve is quite high and makes up 0.92-0.95.

The registered extreme character of dependence of the speed of aggregation $\mathrm{V}_{\mathrm{a}}$ and density of water-coal mixture $\rho_{\mathrm{ws}}$ in Fig. 2 is not yet explained. The hypothesis that was put forward assumes that the presence of extremum-maximum $V_{a}\left(\rho_{w s}\right)$ is the result of action of the competing factors, the progress of two simultaneous processes of formation-destruction of coal-oil aggregates. In liquid pulps, the probability of contact between hydrophobic objects is lower due to the big distances between these objects and, accordingly, decreased frequency of contacts. Thus, contacts of the drops of oil reagent and coal grains, as well as the oiled coal particles, with one another in liquid pulps are rare, single. This explains low rate of aggregation in the region of larger diffused pulps (edge regions on curve $V_{a}\left(\rho_{w s}\right)$ on the left of extremum-maximum). With increasing density of water-coal mixture $\rho_{\mathrm{ws}}$, the mean distance between hydrophobic objects that form coal-oil aggregates decreases, increases, accordingly, the frequency of their contacts (ascending branch of curve $\mathrm{V}_{\mathrm{a}}\left(\rho_{\mathrm{ws}}\right)$ ). At the same time, increasing density of the water-coal mixture $\rho_{\mathrm{ws}}$, activates the process of mechanical friction (contacts, strikes, tangential, angular and frontal forces of interaction) of mineral grains in the turbulent flow of pulp and, accordingly, destruction of the coal-oil aggregates. At a certain value of density of water-coal mixture $\rho_{\mathrm{ws}}$, these two drivers of the processes "formation-destruction" of coal-oil aggregates balance each other at the point of maximum of curve $V_{a}\left(\rho_{w s}\right)$. At further increase in the density of water-coal mixture $\rho_{\mathrm{ws}}$, the process of mechanical friction of mineral grains in the turbulent flow of pulp and, accordingly, the destruction of coal-oil aggregates would prevail. This corresponds to the descending branch of curve $\mathrm{V}_{\mathrm{a}}\left(\rho_{\mathrm{ws}}\right)$ on the right to extremum-maximum. However, hydrophilic rock (high-ash) grains do not participate in the aggregation of coal-oil complexes (granules, agglomerates). They prevent the process of contacting between hydrophobic objects in the pulp and significantly inhibit the process, which explains a decrease in the values of extremum-maximum $\mathrm{V}_{\mathrm{a}}$ for high-ash pulps. 
The hypothesis that was put forward, despite a certain clarity in the explanation of reasons for the existence of extremum-maximum of curve $\mathrm{V}_{\mathrm{a}}\left(\rho_{\mathrm{ws}}\right)$ of the processes on its ascendant and descendant branches is probably somewhat incomplete since it does not consider available intersections of curves $V_{a}\left(\rho_{w s}\right)$ for different ash contents of solid phase of the pulp. Different speeds of the aggregation of pulps with the same density but different ash content of solid phase are predetermined also by differences in the mechanism of the process of aggregation. There are two fundamentally different mechanisms of aggregation:

1) "coalescence" - contact and merging of separate oiled grains;

2) "amalgam" - accumulation of coal grains in an oil film, its subsequent destruction and disintegration into separate elements of which, in the turbulent flow of the pulp, the coal-oil aggregates form.

If the coalescence mechanism is characteristic of pulps with low density and at high ash content of solid phase, the amalgam is of low-ash dense pulps. Obviously, at certain densities and ash contents of solid-phase in the pulp, there are two simultaneous specified mechanisms of aggregation. In fact, this aspect of the nominated hypothesis requires additional study.

We shall note that the range of original pulp densities in the conducted experiments, $\rho_{\mathrm{ws}}=50-600 \mathrm{~g} / \mathrm{cm}^{3}$, is considerably wider than that in articles $[9,11-14]$. At the same time, lower limits of $\rho_{\mathrm{ws}}$ are close (we have $5 \%$, in [9] $7.5 \%$, in [11] - $11.1 \%)$. In general, data on the rational values of concentration of the original pulp in the world practice of oil aggregation of coal are contradictory - they range from $4 \%$ to $50 \%$ [4], which is possible explained by the decisive influence of the density of original pulp on the very type of mechanism of the process of oil aggregation of coal ("coalescence" or "amalgam") - both types of the process are recommended to apply [4]. That is why the chosen range of studies - 5-60\% - into concentration of the original pulp fully agrees with worldwide practice. However, in the studies completed we found optimal combination of factors "ash content of solid phase of the pulp - pulp density" during aggregation of finely dispersed coal the size of $0-0.1 \mathrm{~mm}$, corresponding to the maxima of curve $\mathrm{V}_{\mathrm{a}}\left(\rho_{\mathrm{ws}}\right)$. This makes it possible to significantly reduce duration of the process of oil aggregation of coal under other conditions being equal.

Second series of experiments addresses influence of the kind and consumption of reagent-binder on the results of preparation and dewatering of finely dispersed coal. This factor, according to studies [4, 9, 11-14], is one of the most significant for obtaining quality concentrate and the waste of oiled aggregation of coal. This is confirmed by the results obtained in research.

Ash content of waste $\mathrm{A}_{\mathrm{w}}^{\mathrm{d}}$. The character of curves $\mathrm{A}_{\mathrm{w}}^{\mathrm{d}}\left(\mathrm{Q}_{\mathrm{r}}\right)$, for coal of $1-0 \mathrm{~mm}$ and $2-0 \mathrm{~mm}$ (in accordance with Fig. 3-5) in the region of consumption of reagent-binder of $0-4 \%$ by weight is the same, but the maximum ash content of waste for coal of $1-0 \mathrm{~mm} \mathrm{~A}_{\mathrm{w}}^{\mathrm{d}}=87 \%$, whereas for coal of $2-0 \mathrm{~mm} \mathrm{~A}_{\mathrm{w}}^{\mathrm{d}}=68-69 \%$. This is obviously explained by not a complete opening of intergrowths in coal the size of $2-0 \mathrm{~mm}$. In this case, the aggregation of organic matter is actually completed at relatively low consumption of reagent-binder $4-5 \%$ by weight, the reagent forms thin surface adhesively active films on coal grains. Adhesion of such coal grains predetermines the formation of coal-oil aggregates. Rock grains are not wetted with the hydrophobic reagent and produce waste.

Upon further increase in the consumption of reagent-binder to $16 \%$ by weight, we observe reduction in ash content of waste, due to the mechanical involvement of ash grains or grains-intergrowths in relatively thicker oil films. There occur partially oiled rock grains and retur (usually, fine screening Fig. 12), which are redistributed between the waste and the concentrate interpolluting each other. That is why an increase in the consumption of reagent-binder (over $4-5 \%$ by weight) for the finely dispersed coal whose pelletizing into coal-oil aggregates completes in the region of $5 \%$ by weight, in terms of obtaining waste with maximal ash content, is not expedient. There is a lack of such experimental data on thin $(0-100 \mu \mathrm{m})$ and ultra-thin $(0-50 \mu \mathrm{m})$ coal, which is the task for further research.

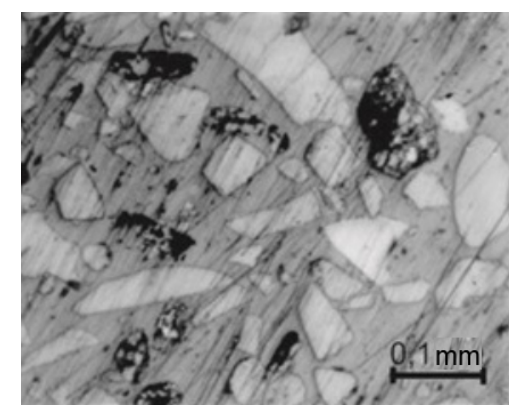

$a$

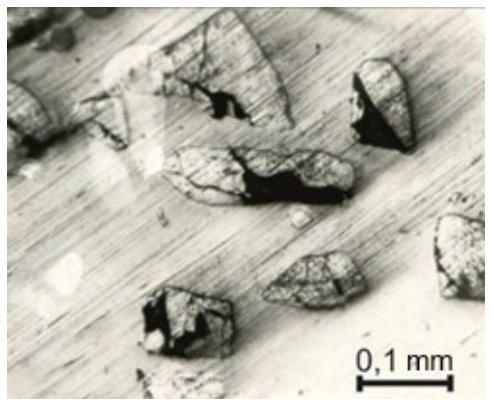

b

Fig. 12. Polished section with partially oiled rock grains and retur (fine screening of micro aggregates and their fragments): $a-$ anthracite; $b$ - coal of grade $\mathrm{G}$

The mean diameter of coal-oil aggregates $d_{a}$ is characterized by directly proportional dependence on the consumption of reagent-binder $Q_{\mathrm{r}}$ (Fig. 3). Form of curve $d_{a}\left(Q_{r}\right)$ for various types of reagent-binder is close, but dimensionality of aggregates varies and is determined by adhesive and cohesive bonds of the components of aggregate. Note that in order to ensure high level of adhesion between reagent and coal, group chemical composition of the coal surface should maximally match chemical composition of the reagent. Maximal strength of adhesive fastening of the reagent on coal surface by the De Broun-Hurwink's rule is achieved at minimal difference in polarity of the participants of adhesion contact [16]. Effectiveness of adhesive fastening of oil reagent on the coal particles is the higher the more the concentration of oxygen functional groups responsible for $\mathrm{H}$-bonds in the 
reagent and on coal surface. In addition, positive effect on the fastening of oil reagent on coal particles is exerted by the presence of the simplest and condensed aromatic compounds with a small amount of benzol nuclei. The positive effect of action of the low-nuclei aromatic compounds with coal surface is predetermined by their complanarity [17].

Humidity of coal-oil aggregates $\mathrm{W}_{\mathrm{tk}}^{\mathrm{r}}\left(\mathrm{Q}_{\mathrm{r}}\right)$ has extremum-maximum (Fig. 4, $a$ ) in the region $\mathrm{Q}_{\mathrm{r}}=8-10 \%$, which corresponds to the early stage of conglomeration of aggregates (refer to conglomerates in Fig. 9-10) and is due to squeezing the moisture between grains in loose conglomerates. Subsequently, with increasing $Q_{\mathrm{r}}$ in the region of $\mathrm{Q}_{\mathrm{r}} \geq 8-10 \%$, inner conglomeration moisture is pressed out by oil reagent from the body of coal-oil aggregates and their total moisture content decreases.

Total yield of coal-oil aggregates $\gamma_{c}\left(Q_{r}\right)$ during oil agglomeration of coal, as it follows from experimental data (Fig. 4, b), reaches $100 \%$, that is, almost all organic coal mass is involved in the process of pelletizing. This occurs at $\mathrm{Q}_{\mathrm{r}}=20 \%$, when not only the hydrophobic coal grains, but coal-rock intergrowths, retur, ultra thin and partially oxidized coal grains are also engaged to pelletizing. In this case, bigger part of the granules has dimensionality $+1.6 \mathrm{~mm}$. Increasing the yield of coal-oil aggregates with increasing consumption of reagent-binder is also demonstrated by local curves $\gamma_{\mathrm{c}}\left(\mathrm{Q}_{\mathrm{r}}\right)$ for particular classes of dimensionality - size grade $1.6-1.0 \mathrm{~mm}$, size grade $1.0-$ $0.5 \mathrm{~mm}$ (Fig. 4, $b$, curves 3 and 4). In this case, the local maximum of curve $\gamma_{c}\left(Q_{r}\right)$ for the aggregates of size grade $1.6-1.0 \mathrm{~mm}$ shifts to the right relative to the local maximum for the aggregates of size grade $1.0-0.5 \mathrm{~mm}$, which corresponds with curves 1 - the total yield of granules, 2 - the yield of granules of class $+1.6 \mathrm{~mm}$.

Special attention should be paid to the structure of aggregates-granules of the type "center-shell" (Fig. 11). The mechanism of formation of aggregates of such structure can be explained by the presence of two mechanisms of contact between oiled coal grains: inertia and turbulent diffusion. Based on data [18, 19], inertia mode is more efficient, which is why larger grains in the pulp of coal of $0-1(2) \mathrm{mm}$ serve as "germs" of aggregates. It is obviously that the outer layer of smaller grains protects larger central grain from shredding. This can be used, for example, during long transportation of coking and steam coal. Establishing technological modes of the process of oil aggregation, under which aggregates mostly possess the structure "center-shell", needs additional research.

A comprehensive approach to the study into oil aggregation of Donetsk coal provides a possibility to assess the prospects of application of this process for the preparation of domestic coal raw materials. However, in this case, there remain a number of unresolved issues. The main are the choice of the rational, from technological and economic point of view, reagents-binders, substantiation of rational technical-economic "niche" for the process of oil aggregation of coal, examination of environmental aspects of the process, as well as determining technological capacities of the method of coal oil aggregation in terms of desulphurization of coal. The latter has a special significance because Donetsk coal differs by a high content of sulphur, rather harmful during subsequent processing and utilization of both coking and steam coal.

\section{Conclusions}

1. By conducting research into effect of the ash content of original coal on the results of oil aggregation, it was established that at an increase in the ash content from $10-15 \%$ to $65-70 \%$, aggregation rate decreases by times. Similarly, at the same duration of the process, at an increase in the ash content of solid phase of the pulp, the extraction of coal mass into coal-oil agglomerate significantly decreases.

2. Examination of the influence of pulp agitation duration on the results of oil aggregation of coal revealed that the duration of pelletizing of coal-oil aggregates is that important factor that compensates for the negative impact of the ash content of solid phase on the progress of the process of aggregation. It was found that the radical increase in the ash content of original material suspends the process only, which lasts longer, but ends, similar to the case with a low ash content in the solid phase, with the formation of coal-oil aggregates. This indicates the existence in the process of coal oil aggregation a property to self-levelling and the possibility of applying for re-preparation of waste, in particular, waste of flotation with the ash content of tails of about $70 \%$.

It was established that for each ash content of solid-phase there is the optimal density of pulp at which speed of aggregation is maximal. We proposed a hypothesis, which explains the existence of these extrema-maxima in the speed of aggregation.

3. Study into the influence of consumption and the type of reagent-binder on the results of oil aggregation of coal showed decisive role of this factor during preparation and dewatering of finely dispersed coal by oil aggregation. In particular, we established a significant influence of consumption of reagent-binder on the ash content of waste, the mean diameter of coal-oil aggregates, humidity of coal-oil aggregates, the total yield of coal-oil aggregates.

When we analyze the obtained results, we may note that the aggregation of organic matter of finely dispersed coal the size of 1(2)-0 mm finishes at relatively low consumption of reagent-binder $4-5 \%$ by weight - in this case, the maximal ash content in waste is achieved. Average diameter of the coal-oil aggregates increases with increasing consumption of reagent-binder and reaches $1.5-2.5 \mathrm{~mm}$ at consumption of reagent $18 \%$ by weight. In this case, for anthracene oil, mean diameter of aggregates is $1.5 \mathrm{~mm}$, for the polymer of benzol production $-1.8 \mathrm{~mm}$, for the mixture "briketin: kerosene" $=1: 3-2.2 \mathrm{~mm}$, for the fuel oil M100 $-2.5 \mathrm{~mm}$. Humidity of coal-oil aggregates at consumption of reagent $18 \%$ by weight and draining for $1-2$ days is $10 \%$ and $8 \%$, respectively. The total yield of coal-oil aggregates during oil agglomeration of coal depends directly proportionally on the consumption of reagent and reaches $100 \%$, that is, almost entire organic coal mass is involved in the process of pelletizing.

Thus, present study demonstrated a possibility of effective preparation of finely- and thinly dispersed Donetsk coal of grade $A$ and grade $G$ the size of $0-0.1 ; 0-1(2) \mathrm{mm}$ and ash content from $10-15 \%$ to $65-70 \%$ by the method of oil aggregation.

A promising direction for further research is the establishment of technological modes of the process of oil of aggregation under which aggregates predominantly have the structure "center-shell". 


\section{References}

1. Filippenko, Y. N. Analysis of the granulometric composition of coal mined [Text] / Y. N. Filippenko, L. A. Morozova, S. O. Fedoseeva // Coal of Ukraine. - 2013. - Issue 3. - P. 12-14.

2. Novak, V. I. A review of modern methods for the enrichment of coal slurries [Text] / V. I. Novak, V. A. Kozlov // GIAB. 2012. - Issue 5. - P. 130-138. - Available at: http://coalprep.ru/publikatsii/obzor-sovremennykh-sposobov-obogashcheniya-ugolnykh-shlamov/

3. Smirnov, V. A. Flotation methods of enrichment of minerals [Text] / V. A. Smirnov, V. S. Beletsky. - Donetsk: East Publishing House, NTSh-Donetsk, 2010. - $496 \mathrm{p}$

4. Beletskyi, V. S. Theory and practice of selective oil aggregation of coal [Text] / V. S. Beletskyi, P. V. Sergeev, Y. L. Papushyn. Donetsk: Grand, 1996. - 264 p.

5. Trass, O. Modified oil agglomeration process for coal beneficiation. iv. pilot-plant demonstration of the simultaneous grinding-agglomeration process [Text] / O. Trass, E. R. Vasquez, P. D. Campbell, E. A. J. Gandolfi, V. R. Koka // The Canadian Journal of Chemical Engineering. - 1994. - Vol. 72, Issue 1. - P. 113-118. doi: 10.1002/cjce.5450720117

6. Sergeev, P. Selective flocculation of coal [Text] / P. Sergeev, V. Beletskyi. - Donetsk: East Publishing House, 1999. - 136 p.

7. Zlobina, E. S. Enrichment of solid hydrocarbon wastes by the oil agglomeration method [Text] / E. S. Zlobina, A. V. Papin, A. Y. Ignatova // Math Designer. - 2016. - Issue 1. - P. 18-21. - Available at: http://www.mathdesigner.ru/journal/2016_1/ articles/2016-1_4.pdf

8. Rafaqat, U. Cleaning of Dukki (Baluchistan) coal by oil agglomeration process [Text] / U. Rafaqat, J. Akhtar, N. U. Sheikh, S. Munir // International Journal of Oil, Gas and Coal Technology. - 2015. - Vol. 9, Issue 1. - P. 79. doi: 10.1504/ijogct.2015.066948

9. Wang, Q. Study on coal recovery technology from waste fine Chinese coals by a vegetable oil agglomeration process [Text] / Q. Wang, N. Kashiwagi, P. Apaer, Q. Chen, Y. Wang, T. Maezono // The Sustainable World. - 2010. doi: 10.2495/sw100311

10. Beletskyi, V. Ennobling of salty coals by means of oil agglomeration [Text] / V. Beletskyi, T. Shendrik // Technical and Geoinformational Systems in Mining. - 2011. - P. 135-139. doi: 10.1201/b11586-23

11. Lin, S. Study on Clean Coal Technology with Oil Agglomeration in Fujian Province [Text] / S. Lin, B. Chen, W. Chen, W. Li, S. Wu // Procedia Engineering. - 2012. - Vol. 45. - P. 986-992. doi: 10.1016/j.proeng.2012.08.270

12. Sahinoglu, E. Amenability of Muzret bituminous coal to oil agglomeration [Text] / E. Sahinoglu, T. Uslu // Energy Conversion and Management. - 2008. - Vol. 49, Issue 12. - P. 3684-3690. doi: 10.1016/j.enconman.2008.06.026

13. Singh, A. V. The Selective Oil Agglomeration of Combustibles in Fines of Low Grade Lignite of Barmer Rajasthan (India) [Text] / A. V. Singh, P. K. Bhargava, R. Singh, K. L. Menaria // Energy Sources, Part A: Recovery, Utilization, and Environmental Effects. - 2012. - Vol. 34, Issue 16. - P. 1491-1496. doi: 10.1080/15567036.2010.485174

14. Temel, H. A. Selective Oil Agglomeration of Lignite [Text] / H. A. Temel, V. Bozkurt, A. K. Majumder // Energy \& Fuels. 2009. - Vol. 23, Issue 2. - P. 779-784. doi: 10.1021/ef8005096

15. Temel, H. A. The Aggoflotation of a Mixture of Subbituminous Coal and Gangue Minerals Using Şirnak Asphaltite and the Concentrate Obtained from Zonguldak Bituminous Coal [Text] / H. A. Temel // Energy Sources, Part A: Recovery, Utilization, and Environmental Effects. - 2010. - Vol. 32, Issue 13. - P. 1248-1259. doi: 10.1080/15567030802706762

16. Debroin, N. Adhesion [Text] / N. Debroin, R. Guvink. - Moscow: Publishing House of the USSR Academy of Sciences, 1949. $580 \mathrm{p}$.

17. Sergeev, P. V. The trial-and modification principles of couplings for the processes of oil agglomeration of coal [Electronic resource] / P. V. Sergeev, V. S. Beletskij, A. T. Elishevich // Solid Fuel Chemistry. - 1993. - Available at: https://www.researchgate.net/publication/291065518_The_trial-and_modification_principles_of_couplings_for_the_processes_of_oil_agglomeration_of_coal

18. Levich, V. G. Physicochemical hydrodynamics [Text] / V. G. Levich. - Moscow: Izdat. Fiz.-mat. liter., 1959. - 700 p.

19. Deryagin, B. V. Study of flocculation of minerals in turbulent mode [Text] / B. V. Deryagin, V. D. Samygin, A. K. Livshits // Colloid Journal. - 1964. - Vol. 26, Issue 2. - P. 179-185. 